\section{The efficacy of skin care products containing glutathione in delivering skin lightening in Indonesian women}

\author{
Kristiana Etnawati, ${ }^{1}$ \\ Dwi Retno Adiwinarni, ${ }^{1}$ \\ Devi Artami Susetiati, ${ }^{1}$ Yusuke Sauchi, ${ }^{2}$ \\ Hitomi Ito ${ }^{2}$ \\ ${ }^{1}$ Dermatology Department, Faculty of \\ Medicine, Universitas Gadjah Mada, \\ Sekip Utara Yogyakarta, Indonesia; \\ ${ }^{2}$ Bio-chemical Division, KOHJIN Life \\ Sciences Co. Ltd., 1-3, Yurakucho \\ 1-chome, Chiyoda-ku, Tokyo, Japan
}

\begin{abstract}
Glutathione is a potent antioxidant, which is widely used in skin care products for skin lightening especially in the Asian market. Presently, there was only one study of topical 2\% oxidized glutathione (GSSG) in Philipino women, further study is needed to evaluate the efficacy and safety of cosmetic products containing glutathione. A double blind randomized clinical trial study was conducted in Yogyakarta, Indonesia, in 74 healthy Indonesian women, with average age $33.3 \pm 5.9$ years when subjects participated in the study. Each subject received supervised applications of Facial Wash twice a day, Day Cream with sunscreen and Night Cream. The subjects were divided into 3 groups based on the active ingredients of the tested products, which included glutathione reduced (GSH) $0.1 \%$, GSH $0.5 \%$, and without GSH. The effects of the tested products in lightening skin color and pigmentation were measured colorimetry with Chromameter Minolta for L*. Compared to a baseline, there were significant increases of $\mathrm{L}^{*}$ (lightness) or $\Delta \mathrm{L}^{*}$ detected as early as week 2 in which group of $\mathrm{GSH} \quad 0.1 \%$ were significantly higher compared to group of GSH $0.5 \%$ and group without GSH. Hyperpigmented lesions also improved, where GSH $0.5 \%$ group showed its superiority compared to others groups in week 8 . The undesired effect were few minutes mild tingling sensation after night cream, and worsening of acne in all tested products. Conclusion skin care products containing GSH $0.1 \%$ and $0.5 \%$ were effective in facial skin lightening.
\end{abstract}

\section{Introduction}

Fair and flawless skin is a concept of beauty care especially in colored ethnic groups. Consequently, the dream of having light colored skin becomes an exploited arena by the cosmetic industry. There are many reports of adverse events of misuse of bleaching agents for skin lightening of normal skin such as mercury, corticosteroid and hydroquinone. Moreover some countries have banned the use of hydroquinone for cosmetic purposes. ${ }^{1,2}$ Nevertheless, the need of gaining light colored skin apparently cannot be prevented or prohibited. One study showed despite label warnings, $2.6 \%$ of pregnant women in Sweden still recklessly using bleaching agents. ${ }^{3}$ Consequently it appears that there is a need for a lightening agent, which is safe and effective. An interesting agent is glutathione, a cysteine-glycine-glutamate tripeptide, which exerts several effects on melanogenesis through different mechanisms involving the function and cellular transport of tyrosinase. ${ }^{4}$ Its skin-lightening effect results from direct as well as indirect inhibition of tyrosinase enzyme and and switching from eumelanin to phaeomelanin production. 5,6

The efficacy of systemic glutathione in skin lightening had been studied currently in Thailand, Philipines and Indonesia which showed decreased of melanin indices within 2- 4 weeks, ${ }^{7-9}$ however there are no established long-term safety studies and the risk of potentially adverse events led to serious questioning on the use of the systemic glutathione just for temporary skin lightening. ${ }^{10}$ Topical glutathione could be used as one alternative if skin lightening is still needed. While currently products with topical GSH are abundant in the commercial cosmetic market, only one randomized clinical study of had been conducted to evaluate the efficacy and safety in Phillipino women. ${ }^{11}$ Currently, according to Indonesia National Agency of Food and Drug Control, there are 68 registered cosmetics containing glutathione (GSH). ${ }^{12}$ However there is no evidence of clinical efficacy and safety of topical GSH in Indonesia. More studies are needed to evaluate the efficacy of the developed glutathione products, especially in Indonesian women, who are currently the prevalent users of lightening skin care products. This in vivo study evaluated active and supportive ingredients comprehensively and simultaneously. Furthermore it provides accurate information on the product safety to the manufacturing companies, community, customers and regulatory board.

\section{Materials and Methods}

This research is a double-blind randomized controlled study. We enrolled 81
Correspondence: Kristiana Etnawati, Dermatology Department, Faculty of Medicine, Universitas Gadjah Mada, Radiopoetro Building 3rd Floor, Sekip Utara, 55281, Yogyakarta, Indonesia.

Phone/fax: +62-274-560700

E-mail: etnawati@ugm.ac.id

Key words: Glutathione, skin lightening, hyperpigmented lesions, colorimetry

Acknowledgments: KOHJIN Life Science, a subsidiary of Mitsubishi Corporation Life Sciences, provided GSH (OPITAC ${ }^{\text {TM }}$ Glutathione, Japanese Government GMP \#3566, US FDA GRAS \#GRN000293) and partial financial support for this work. However, KOHJIN Life Science was not involved in data analysis or manuscript preparation

Contributions: All authors contributed equally.

Conflict of interest: The authors declare no conflict of interest.

Received for publication: 1 February 2018. Accepted for publication: 6 February 2018.

This work is licensed under a Creative Commons Attribution-NonCommercial 4.0 International License (CC BY-NC 4.0).

CCopyright K. Etnawati et al., 2019

Licensee PAGEPress, Italy

Dermatology Reports 2019; 11(s1):8013

doi:10.4081/dr.2019.8013

healthy women, which have Fitzpatrick skin phototype IV, V, were aged $33.3 \pm 5.9$ years, with Body Mass Index 25.4 \pm 5.6 .

Reasons for exclusion from the study were use of skin lightening or anti-aging products in the previous four weeks, current pregnancy, lactation, using hormonal contraceptive, intake of any medications, including supplements.

Each participant received day cream, night cream and facial wash which was applied under supervision of study officer to certify compliance. The participants were divided randomly into three groups depending on the concentration of the GSH in the skin care products, which were $0.1 \%, 0.5 \%$ and without GSH. All of the day cream contains octocrylene, Butyl Methoxydibenzoylmethane, Bis-ethylhexyloxyhenol Methoxyphenyl Triazine, and Titanium Dioxide with SPF 15.

Biophysical evaluations were performed at baseline data and every two weeks for a total period of 8 weeks, while safety evaluation were conducted by a trained consultant and certified Dermatologist, and confirmed with standardized digital photography. Safety assess- 
ment was determined based on signs of dermatitis and acne of the face at baseline, every 2 weeks of treatment until week 8 . While skin color measurements were obtained from the middle of the forehead and cheek, also from one pigmented area on the face. Reading of skin color or $\mathrm{L}^{*}$ were conducted with a Chromameter Minolta CR 200. Three readings were taken from each distinct location of normal skin from the forehead and left and right cheeks, and the averages of readings were recorded. The colorimetry was also used to measure readings from one spot of hyperpigmentation lesions.

Informed consent was obtained prior to the subjects inclusion, and the study was conducted in accordance with Declaration of Helsinki. Ethical Clearance Approval was obtained before the commencement of the study from the Medical and Health Research Ethics Committee (MREC) of the Universitas Gadjah Mada.

\section{Results}

Seventy four participants completed the 8 weeks study, since 7 subjects could not comply with the daily product application due to the distance from the study place and were considered to be drop outs from the study.

\section{Skin lightening effects of normal facial skin}

Compared to baseline there are significant percentage increases of $\mathrm{L}^{*}$ or $\Delta \mathrm{L}^{*}$ of the normal non-lesional skin of the face detected at week 8 in the 2 groups who received the GSH products $(\mathrm{p}<0.05)$, although the increase was highest with products containing GSH $0.1 \%$, however statistically there were no significant differences of the $\Delta \mathrm{L}^{*}$ between the tested groups (Figure 1).

\section{Skin lightening effect on hyperpig- mented lesions}

Additionally from hyperpigmented lesions of the face (lentigines and melas$\mathrm{ma}$ ), there was also significant increases of percentage of $\mathrm{L} *$ or whitening of the lesions compared to baseline which was highest in GSH $0.5 \%$ group $(\mathrm{p}<0.05)$ (Figure 2).

\section{Side effects}

Mild side effects were some tingling sensation after night cream application which disappeared after a few minutes, which were $7.4 \%$ in night cream contain GSH $0.1 \%, 12.5 \%$ night cream contain $0.5 \% \mathrm{GSH}$, and $8.7 \%$ in placebo with ave- rage $9.5 \%$ of total subjects. The development and worsening of acne were also detected in $18.5 \%$ subjects from GSH $0.1 \%$ group, $8.3 \%$ from GSH $0.5 \%$ group, and $8.7 \%$ from placebo group or average of $11.8 \%$ of the total subjects.

\section{Discussion}

All tested skin care product groups showed significant skin lightening compared to baseline, including skin care products without GSH or placebo. While the placebo using in this study was skin care product without GSH, however it contained sunscreen which was applied once a day in the morning. This result points to the importance of sun avoidance or sunscreen in any skin lightening products to obtain the best results. However the GSH groups $(0.1 \%$ and $0.05 \%$ ) still showed superiority over the placebo in skin lightening, especially in hyperpigmented lesions.

The skin care products which were tested in this study were comprised of facial wash which was used twice a day before application of day cream and night cream, in which the tested combination of skin care products was intended to increase the absorption of active ingredients especially GSH.

The mechanism of GSH in skin lightening occurs through tyrosinase inhibition and also activation of the phaeomelanin pathway. The effect of skin lightening is more clearly pronounced in hyperpigmented lesions, which fits with the finding that

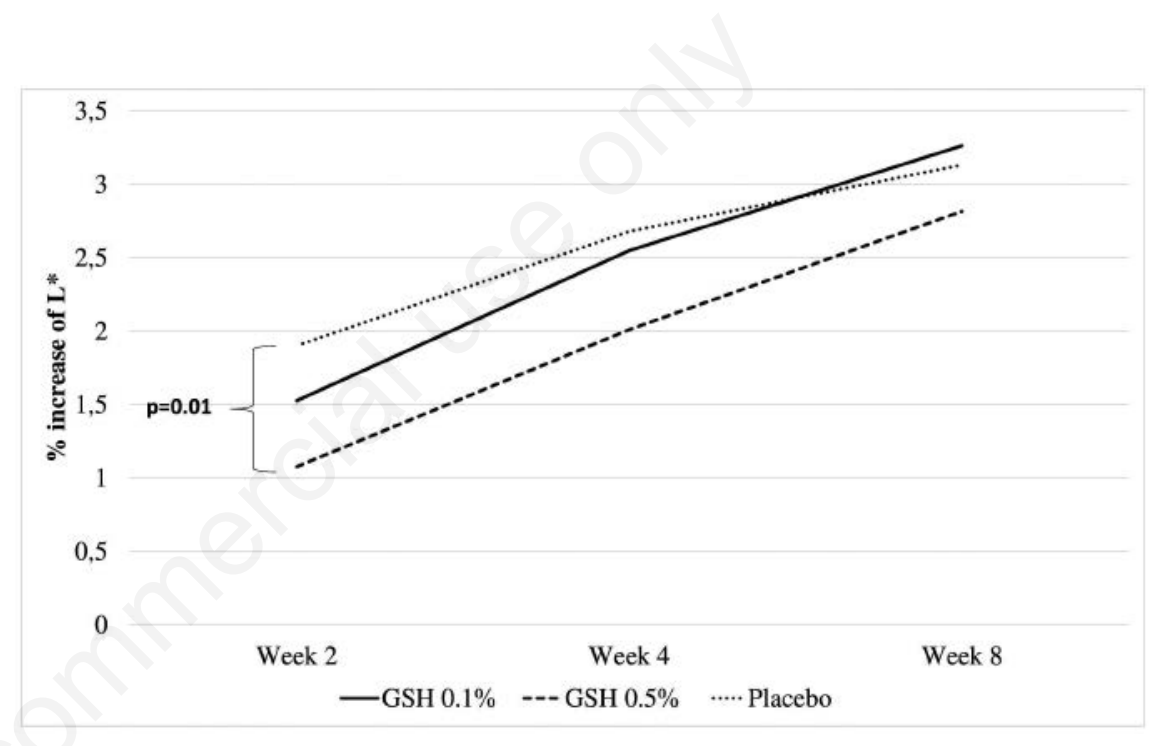

Figure 1. The increase of lightness in normal facial of skin which is best after treatment at week 8 with skin care products containing GSH $0.1 \%$.

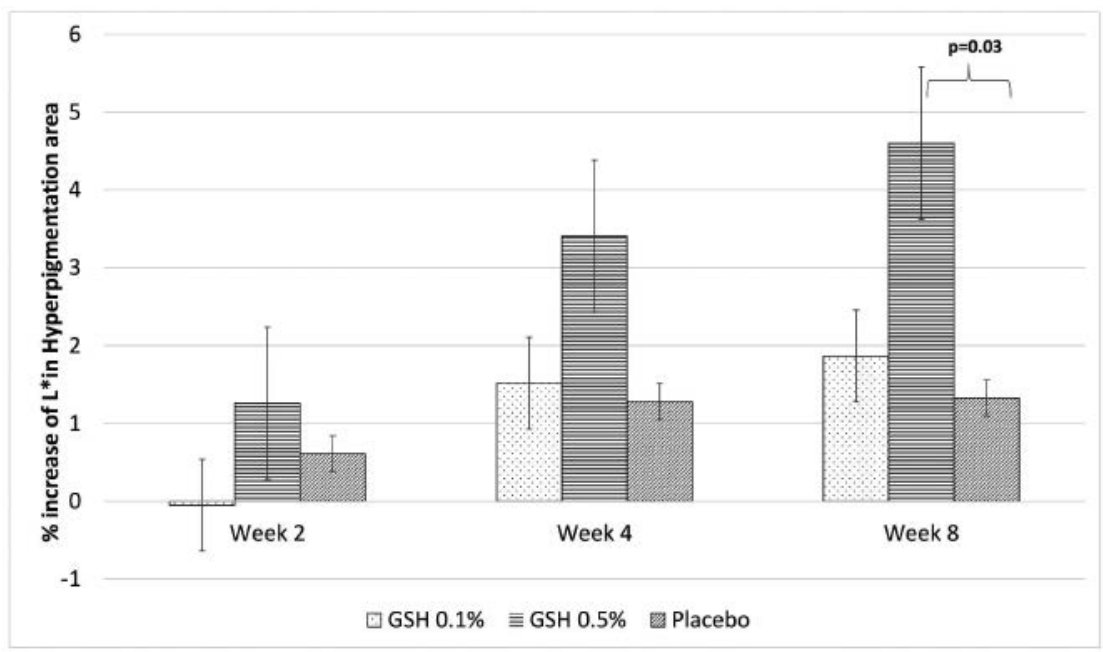

Figure 2. The increase of lightness in hyperpigmented lesion of the face which is best after treatment at week 8 with skin care products containing GSH $0.5 \%$. 
GSH affects new melanogenesis. The antioxidant properties of glutathione were shown in other study of the linolenic glutathione conjugate (lin-GSH) $2 \%$ cream. In which the application of lin-GSH before UVB irradiation showed the significant decrease of Minimal Erythematous Dose (MED), while application of the lin-GSH $2 \%$ cream after irradiation did not show any change in MED. ${ }^{13}$ This study showed the antioxidant properties of glutathione which its pharmacokinetic modified via acetylation with long chain polyunsaturated fatty to improve its passage through phospholipidic membranes.

One clinical study in Philipino women with topical $2 \%$ oxidized glutathione (GSSG) showed a decrease of melanin index, an increase in moisture content of the stratum corneum, suppression of wrinkle formation, and improvement in skin smoothness. ${ }^{11}$ This study also showed not only skin lightening in Indonesian women, but also the reduction of, melasma, and lentigines as signs of photoaging which is especially due to long term expose to Ultraviolet B (UVB).

\section{Conclusions}

In conclusion, the present study demonstrates the lightening effect of daily applications of a combination of day cream SPF 15, night cream and facial wash containing GSH $0.1 \%$ and $\mathrm{GSH} 0.5 \%$ in healthy Indonesian female subjects for an 8 week period, based on colorimetric assessment. Products containing GSH $0.1 \%$ were found to be significantly superior compared to products containing GSH $0.5 \%$ and products without GSH in skin lightening of normal sun exposed skin, while products con- taining GSH $0.5 \%$ work better on hyperpigmented lesions. The worsening of acne found in all groups during the study needs further consideration in reformulating the products, especially the sunscreen used in hot humid areas of the world, since the use of sunscreen is important to achieve the best result of any lightening or anti-aging products. Nine and a half percent of subjects experienced a tolerable, mild tingling sensation during the night cream application. No other significant side effects due to the tested products were found during the study.

\section{References}

1. Sinha A, Kar S, Yadav N, Madke B. Prevalence of Topical Steroid Misuse Among Rural Masses. Indian J Dermatol 2016; 61:119.

2. Dey VK. Misuse of topical corticosteroids: A clinical study of adverse effects. Indian Dermatol Online J 2014;5:436-40.

3. Darj E, Infanti JJ, Ahlberg BM, Okumu J. The fairer the better? Use of potentially toxic skin bleaching products. Afri Heal Sci 2015;15:107480 .

4. Gillbro JM, Olsson MJ. The melanogenesis and mechanisms of skinlightening agents - Existing and new approaches. Int J Cosmet Sci 2011;33: 210-21.

5. Villarama CD, Maibach HI. Glutathione as a depigmenting agent: an overview. Int J Cosmet Sci 2005; 27:147-53

6. Alena F, Dixon W, Thomas P, Jimbow $\mathrm{K}$. Glutathione plays a role in the depigmenting and melanocytotoxic action of N-acetyl-4-S-cysteami- nylphenol in black and yellow hair follicles. J Invest Dermatol 1995;104: 792-7.

7. Handog EB, Datuin MSL, Singzon IA. An open-label, single-arm trial of the safety and efficacy of a novel preparation of glutathione as a skinlightening agent in Filipino women. Int J Dermatol 2016;55:153-7.

8. Arjinpathana N, Asawanonda P. Glutathione as an oral whitening agent: A randomized, double-blind, placebocontrolled study. J Dermatol Treat 2012;23:97-102.

9. Betty Ekawati S, T. Agoeng, Dwi Retno, Kristiana Etnawati. Pengaruh Berbagai Kombinasi Dosis Pemberian Vitamin C dan Glutation Injeksi pada Warna Kulit Evaluasi Kromametrik Terhadap Tujuh Kasus. Media Dermatovenereologica Indonesiana 2002;29:19-24.

10. Dadzie OE. Unethical skin bleaching with glutathione. BMJ 2016;354.

11. Watanabe Fumiko; Hashizume E, Chan GP. Skin-whitening and skin-conditionimproving effects of topical oxidized glutathione: a double-blind and placebo-controlled clinical trial in healthy women. Clin Cosmet Investig Dermatol 2014;7:267-74.

12. BPOM RI. Cek Produk BPOM 2017. [cited 18 October 2017]. Available from: http://cekbpom.pom.go. id/index. php/home/produk/d1 ebfca71dae702542 49c2e6ec3d18f4/12/row/10/page/1/ord er/4/DESC/search/1/GLUTA

13. Grandi V, Milanesi N, Sessa M, et al. Efficacy and safety of s-acyl glutathione $2 \%$ cream vs. Placebo against UVBinduced erythema: A Randomized, Double-Blinded Clinical Trial G Ital Dermatol Venereol 2017. 